\title{
AS REPERCUSSÕES DOS RESULTADOS DO ENADE NAS INSTITUIÇÕES FOMADORAS DE DOCENTES: UM ESTADO DO CONHECIMENTO.
}

\author{
Apresentação: Comunicação oral. \\ Autora Principal: Jessica Flaíne dos Santos Costa. ${ }^{1}$ \\ Coautora: Kátia Silva Cunha. ${ }^{2}$
}

\begin{abstract}
RESUMO: O presente artigo apresenta e discuti os dados referentes a pesquisa que deu origem ao estado do conhecimento que compõe a dissertação intitulada "As contribuições do ENADE para o curso de Pedagogia da UFPE- CAA: um olhar para o percurso formativo de Pedagogos/as". O mesmo aponta a seleção de trabalhos científicos que têm se voltado, nas últimas décadas (2004 a 2015), às investigações referentes ao modo como as instituições formativas de docentes têm lidado com os escores gerados pela participação de seus estudantes no ENADE (Exame Nacional de Desempenho de Estudantes). Os levantamentos foram realizados nos bancos do Scielo, da CAPES, do Repositório Institucional da UFPE, da Biblioteca Digital Brasileira de Teses e Dissertações, do Instituto Brasileiro de Informação em Ciência e Tecnologia (BDT-IBICT) e do Repositório Institucional da UnB. Foram encontrados 14 trabalhos que discutem a centralidade e os sentidos atribuídos à avaliação no espaço da educação superior, abordando diferentes questões e trazendo grandes contribuições à compreensão sobre o modo como as políticas de avaliação externa, em especial o ENADE, têm sido consideradas para conceber e regular as ações de formação de docentes. Ao final apresentamos a distinção e relevância da nossa pesquisa para o contexto local de Caruaru-PE.
\end{abstract}

Palavras-chave: Políticas de Avaliação Externa, ENADE, Formação de Docentes, Estado do Conhecimento.

\section{INTRODUÇÃO}

O presente artigo é resultado de uma parcela da dissertação, ora em construção, intitulada "As contribuições do ENADE para o curso de Pedagogia da UFPE- CAA: um olhar para o percurso formativo de Pedagogos/as", que vem sendo desenvolvida no âmbito do curso de Mestrado em Educação Contemporânea (PPGEDUC) da Universidade Federal de Pernambuco- Centro Acadêmico do Agreste (UFPE- CAA),

\footnotetext{
1 Mestranda pelo Programa de Pós-graduação em Educação Contemporânea (PPGEDUC), da Universidade Federal de Pernambuco- Centro Acadêmico do Agreste (UFPE- CAA).

2 Docente do Programa de Pós-graduação em Educação em Ciências e Matemática (PPGECM) e do Núcleo de Formação Docente, ambos da Universidade Federal de Pernambuco- Centro Acadêmico do Agreste (UFPE- CAA).
} 
com orientação da Professora Dra. Kátia Silva Cunha. O mesmo tem a intenção de apresentar e discutir os dados referentes a pesquisa que deu origem ao estado do conhecimento que compõe a dissertação, através do qual apontamos a seleção de trabalhos científicos que têm se voltado, nas últimas décadas (2004 a 2015), às investigações que concernem ao modo como as instituições formativas de docentes têm lidado com os escores gerados pela participação de seus estudantes no ENADE (Exame Nacional de Desempenho de Estudantes).

O ENADE integra, como um dos componentes, o Sistema Nacional de Avaliação da Educação Superior, o SINAES, que foi instituído pela Lei $\mathrm{n}^{\circ} 10.861$, de 14 de abril de 2004, sendo a sua efetivação, de responsabilidade do Ministério da Educação (MEC), em parceria com o Instituto Nacional de Pesquisas Educacionais Anísio Teixeira (INEP) e, com as IES. Considerando o Art. $5^{\circ}, \S 1^{\circ}$, da Lei aqui mencionada, o Exame tem a função de:

Aferir o desempenho dos estudantes em relação aos conteúdos programáticos previstos nas diretrizes curriculares do respectivo curso de graduação, suas habilidades para ajustamento às exigências decorrentes da evolução do conhecimento e suas competências para compreender temas exteriores ao âmbito específico de sua profissão, ligados à realidade brasileira e mundial e a outras áreas do conhecimento.

Sendo assim, se pretende a avaliar todos os aspectos que giram em torno dos eixos: "o ensino, a pesquisa, a extensão, a responsabilidade social, o desempenho dos alunos, a gestão da instituição, o corpo docente, as instalações e vários outros aspectos" (portal do INEP: http://portal.inep.gov.br/web/guest/superior-sinaes). Neste sentido, tem a intenção de, através de prova e questionários, aferir o desempenho de estudantes de graduação de instituições públicas e privadas, em caráter obrigatório, e em período trienal, para diagnosticar se habilidades e competências previstas nas diretrizes curriculares que orientam a constituição dos currículos dos cursos, foram, de fato, alcançadas, para, com base em seus resultados, impulsionar as modificações necessárias nos mesmos e no aspecto estrutural das instituições de acordo com suas necessidades.

Temos como interesse central na pesquisa de mestrado, investigar as influências dos resultados do ENADE para a análise, reflexão e modificações no currículo do curso de Pedagogia da Universidade Federal de Pernambuco- Centro Acadêmico do Agreste (UFPE- CAA). Nosso intuito, é entrar em contato com a referida IES para sabermos como esta têm recebido os resultados do exame, que destinos têm atribuído a eles e qual 
a relevância deste processo, no que diz respeito ao aperfeiçoamento das práticas de formação que vêm proporcionando aos seus estudantes. Para tanto, os nossos objetivos têm nos conduzido a compreender de que forma os resultados do ENADE têm sido levados em consideração pela UFPE- CAA, no âmbito específico do curso de Pedagogia, procurando investigar como os resultados do ENADE têm chegado à IES, de que maneiras estes resultados são considerados pela coordenação do curso e gestão pedagógica da instituição e quais as influências exercidas pelos resultados do ENADE na reflexão pedagógica dos coordenadores do curso e da gestão pedagógica para a reorganização curricular do curso.

A partir disto, buscamos realizar um levantamento nos bancos de teses e dissertações, a nível nacional. Figuram entre eles o Scielo, a CAPES, o Repositório UFPE, a Biblioteca Digital Brasileira de Teses e Dissertações e o Repositório Institucional da Universidade de Brasília (UNB). Os trabalhos selecionados vêm ao longo das últimas décadas investigando e fazendo uma análise da prática de avaliação da educação superior que vem se desdobrando no Brasil, e tendem a apontar as lacunas e os avanços que estas políticas têm alcançado, bem como as interferências destes processos no contexto das IES e da formação oferecida. Diante da realização deste levantamento, buscamos apresentar as aproximações e os distanciamentos empreendidos pela nossa pesquisa, fazendo um paralelo com a gama de conhecimentos consolidada na área, para justificar o diferencial que norteará a nossa discussão.

\section{METODOLOGIA}

A realização deste levantamento se dá no sentido de promover um contato e um aprofundamento com grande parte dos recursos bibliográficos que discorrem sobre a área de conhecimento por nós abordada, permitindo que cheguemos a identificação da relevância e do diferencial que será conquistada pela nossa pesquisa. Neste sentido, concordamos com Ferreira (2002, p. 258), quando reflete que:

Nos últimos quinze anos tem se produzido um conjunto significativo de pesquisas conhecidas pela denominação "estado da arte" ou "estado do conhecimento". Definidas como de caráter bibliográfico, elas parecem trazer em comum o desafio de mapear e de discutir uma certa produção acadêmica em diferentes campos do conhecimento, tentando responder que aspectos e dimensões vêm sendo destacados e privilegiados em diferentes épocas e lugares, de que formas e em que condições têm sido produzidas certas dissertações de mestrado, teses de doutorado, publicações em periódicos e comunicações em anais de congressos e seminários. Também são conhecidas por realizarem uma metodologia de caráter inventariante e descritivo da 
produção acadêmica e científica sobre o tema que busca investigar, à luz de categorias e facetas que se caracterizam enquanto tais em cada trabalho e no conjunto deles, sob os quais o fenômeno passa a ser analisado.

Os materiais que têm sido produzidos em torno da temática de investigação elegida para trabalho, permite a tomada de conhecimento das discussões e informações que têm se constituído ao longo do tempo pelos/as estudiosos que também se debruçam no desafio de compreender e produzir conhecimentos sobre seu objeto de pesquisa. Essa análise permite que o/a pesquisador/a conheça diferentes experiências e empreenda aprofundamentos epistemológicos quando no contato com outras perspectivas teóricas sobre a sua área de estudo. A partir de então, torna-se possível compreender o que marca o diferencial e a inovação na nova proposta de pesquisa, que a caracterizará como única e distinta no conjunto das produções no qual estará inserida.

Sendo assim, foram realizadas buscas de pesquisas, sendo elas dissertações e teses, que vêm abordando a partir de 2004, época de implantação do SINAES, a questão das políticas de avaliação e aprimoramento da educação superior no Brasil, as suas intenções e os impactos reais decorrentes de sua implantação. Os levantamentos foram realizados no período de janeiro de 2016, nos bancos do Scielo, CAPES, Repositório Institucional da UFPE (níveis regional e nacional), na Biblioteca Digital Brasileira de Teses e Dissertações, do Instituto Brasileiro de Informação em Ciência e Tecnologia (BDT-IBICT) e no Repositório Institucional da Universidade de Brasília (UNB), sendo realizadas com base em palavras-chave, como ENADE, ENADE nos cursos de Pedagogia e políticas de avaliação do ensino superior. Ao todo foram encontrados 14 trabalhos que giram em torno da centralidade e dos diferentes sentidos atribuídos à avaliação no espaço da educação superior, desde as antigas políticas de avaliação da educação superior, criadas na década de 1990 até o presente momento, com a implantação do SINAES.

\section{RESULTADOS E DISCUSSÕES}

\section{Estado do conhecimento: inteirando-se das discussões correntes sobre a política nacional de avaliação externa.}

No banco de dados do Scielo, foram encontrados 6 trabalhos que discorrem a respeito do percurso histórico da elaboração das políticas de avaliação da educação superior no Brasil e mais especificamente dos usos dos resultados do ENADE para análise dos cursos de formação de docentes, entre eles o de Pedagogia. 
O primeiro trabalho é o de Brito (2007), e está intitulado "ENADE 2005: perfil, desempenho e razão da opção dos estudantes pelas Licenciaturas". O mesmo analisa ${ }^{3}$ o perfil dos discentes dos cursos de Licenciaturas que se submeteram ao ENADE 2005, bem como o desempenho destes na categoria de Formação Geral e as razões que apontam para a escolha de cursos de formação de professores/as, além de buscar estabelecer algumas variáveis selecionadas, procurando verificar quais as diferenças significativas. Os resultados da pesquisa mostraram que os estudantes de Licenciaturas concentram-se em cursos noturnos de IES privadas e são oriundos predominantemente do ensino médio público; a principal razão para a escolha da Licenciatura é o desejo de ser professor. O segundo trabalho, é o de Bordas et al (2008), com o título "O olhar da comissão assessora de avaliação sobre o ENADE da área de Pedagogia- 2005”. Este apresenta o trabalho realizado entre maio e novembro de 2005, pela Comissão Assessora de Avaliação do ENADE da área de Pedagogia, incumbida de propor diretrizes, objetivos e outras especificações para a construção dos instrumentos de avaliação a serem aplicados aos estudantes ingressantes e concluintes participantes do Exame de 2005. A terceira produção, por nós selecionada, é de Barbosa, Freire e Crisóstomo (2011), de título "Análise dos indicadores de gestão das IFES e o desempenho discente no ENADE". Sua intenção foi analisar possíveis relações entre indicadores de gestão e desempenho discente. Para tanto, pesquisou uma amostra de 52 IFES no período de 2006 a 2008. Os resultados indicaram que, de fato, alguns indicadores de gestão parecem ser capazes de influenciar o desempenho discente. Este é o caso, por exemplo, do custo por aluno que apresentou um efeito positivo sobre os desempenhos dos alunos.

O quarto trabalho, é de Barreyro e Rothen (2014), denominado de "Percurso da avaliação na educação superior nos governos Lula", e visou analisar a política de avaliação da educação superior desenvolvida durante os governos Lula (2003-2010), através de uma pesquisa documental. O ponto de partida foi mostrar que o Sistema Nacional de Avaliação da Educação Superior (SINAES) implicou uma mudança na lógica da avaliação imperante. O quinto trabalho, de Bertolin e Marcon (2015), de título “O (des)entendimento de qualidade na educação superior brasileira- das quimeras do

\footnotetext{
${ }^{3}$ As descrições de cada trabalho, neste artigo apresentado, foram retiradas e sintetizadas de seus resumos, escritos por seus respectivos autores/as. Para maiores informações, consultar os trabalhos na íntegra. $\mathrm{O}$ acesso aos mesmos torna-se possível através de procura com base nas informações disponíveis nas referências bibliográficas.
} 
provão e do ENADE à realidade do capital cultural dos estudantes", aborda inicialmente o conceito de capital cultural de Bourdieu e revisa pesquisas quantitativas sobre eficácia escolar e os fatores determinantes do desempenho dos alunos. Posteriormente, analisa estudos e dados sobre a importância do contexto socioeconômico dos estudantes e seus desempenhos na educação superior. Por fim, conclui destacando evidências da maior relevância do contexto do aluno em relação ao "fator curso" nos resultados desses instrumentos.

O sexto e último trabalho encontrado no banco do Scielo, foi o de Lacerda e Ferri (2015), com o título "Relações entre indicadores de qualidade de ensino e desempenho de estudantes dos cursos de Pedagogia do Brasil no Exame Nacional de Desempenho de Estudantes", que tem como objetivo investigar as relações entre os indicadores presentes no Conceito Preliminar de Curso (CPC) dos cursos de Pedagogia no Brasil, com base nos resultados do ENADE (2008) para essa área. Os resultados apresentados, segundo as combinações de organização acadêmica e categoria administrativa das IES brasileiras, mostraram relações significativas dos percentuais de doutores e de mestres com o ENADE e o IDD, sendo mais fortes nas universidades estaduais e nas faculdades privadas integradas. Concluiu-se que a relação entre os indicadores de qualidade e o desempenho foi dependente da combinação entre organização acadêmica e categoria administrativa, de modo que sugere que aprimoramentos no CPC poderiam considerar tais diferenças entre as IES.

Nosso segundo banco de teses e dissertações escolhido para levantamento, foi o da CAPES. Nele encontramos apenas o trabalho de Rangel (2010), intitulado de "O Exame Nacional de Desempenho de Estudantes no curso de Pedagogia da UnB: avanços, limites e desafios". O mesmo buscou estudar o ENADE no curso de Pedagogia da UnB e compreender a importância atribuída a este instrumento como política pública de avaliação da educação superior implementada pelo MEC, por meio do INEP, nas IES do Brasil, especialmente em uma universidade pública. Concluiu-se que a centralidade do ENADE é ocasionada por diferentes fatores, entre eles o uso que é feito de seus resultados que revela uma incompreensão de seus objetivos. Os indicadores e as informações produzidas pelo ENADE têm contribuído efetivamente com o processo de regulamentação exercido pelo MEC e pouco com o processo avaliativo como indutor da qualidade da educação superior. O trabalho revelou que também que não houve nenhuma estratégia especial na realização do ENADE 2008 no curso de Pedagogia da 
UnB, embora documentos internos da instituição apontem para a necessidade de estimular mais a participação dos estudantes, que em 2008 pautou-se prioritariamente por duas variáveis: (i) obrigatoriedade do exame e (ii) o desejo de contribuir com a melhoria da qualidade do curso.

O terceiro banco de teses e dissertações, foi o Repositório Institucional da UFPE. No levantamento realizado neste banco, foram encontrados trabalhos que tratam da análise da efetivação das políticas de avaliação da educação superior considerando seus diferentes âmbitos, na intenção de mobilizar reflexões que estejam voltadas ao acompanhamento da percepção e dos impactos gerados pelas modificações ocorridas nestas políticas com o advento da implantação do Sistema Nacional de Avaliação da Educação Superior (SINAES), que substituiu a antiga política, o Exame Nacional de Cursos (ENC), que vigorou de 1996 a 2003. Nele foi possível encontrar 5 trabalhos. O primeiro foi o de Ferraz (2006), que tem como título "Políticas de avaliação para a educação superior: um estado analítico sobre as práticas discursivas nos governos de Fernando Henrique Cardoso e Luiz Inácio Lula da Silva”, e analisou comparativamente as políticas de avaliação para a educação superior dos governos de Fernando Henrique Cardoso e Luiz Inácio Lula da Silva, buscando, através da Análise de Discurso Textualmente Orientada (ADTO) de Norman Fairclough, analisar as práticas discursivas a partir da interdiscursividade, da intertextualidade e do discurso como prática social, com vistas à captar o sentido implícito no material recolhido. Como resultados, foi observado que a política de avaliação no governo FHC, caracterizou-se pela preocupação com o desempenho institucional, através de iniciativas de avaliação isoladas. A avaliação assumiu um caráter somativo e classificatório, por basear-se numa concepção tecnicista que enfatizava o controle por desempenho, a hierarquização e a produtividade, segundo uma lógica economicista-instrumental.

O segundo trabalho foi o de Silva (2009), denominado "Avaliação do ensino superior: a dinâmica de implementação do SINAES nas universidades federais no tocante ao instrumento de avaliação interna - CPA”. Este trata da dinâmica de implementação do SINAES nas universidades federais, referente à avaliação interna, tendo como objetivo a análise das políticas de avaliação institucional formulada e coordenada pelas Comissões Próprias de Avaliação (CPA). Foi apontada a necessidade de haver uma reflexão atenta sobre o processo de participação, os resultados alcançados e o impacto dos trabalhos da CPA nas IFES, para o aprimoramento do processo de 
autoavaliação no contexto da dinâmica da implementação do SINAES. Concluiu-se que a falta de familiaridade com a teoria e a prática da avaliação tenha favorecido não somente o descompasso conceitual, mas também o desencontro entre os objetivos propostos e as metodologias empregadas no trabalho desenvolvido pelas CPAs. O terceiro trabalho, foi o de Cunha (2011), com o título "O discurso da avaliação institucional trajetória articulada no campo das políticas educacionais: um estudo de caso". O mesmo analisa o discurso sobre a avaliação institucional na Universidade de Pernambuco e, de forma específica, a relação entre a avaliação institucional e os processos de mudança institucional.

O quarto trabalho, "Aspectos contextuais e metodológicos da avaliação da qualidade da educação superior brasileira: uma análise dos indicadores utilizados pelos órgãos reguladores nos processos de avaliação dos cursos de graduação", de Silva (2013), elegeu como foco de estudo os indicadores empregados pelo INEP, na avaliação dos cursos de graduação. Evidenciou-se que a ausência e/ou presença incipiente das características que todo indicador deve possuir é um elemento significativo da imprecisão da informação e da ausência de associação com a qualidade do ensino. Observou-se ainda que a presença das relações estocásticas no processo educativo reduz o grau de controle dos indicadores, se comparado a situações determinísticas, reorientando a forma de tratá-los e interpretá-los.

O quinto e último trabalho, foi o de Silva (2015), “Avaliação institucional no Sistema Nacional de Avaliação da Educação Superior (SINAES)", buscou compreender a articulação entre avaliação interna e externa a partir da perspectiva tecnológica, política e cultural e como esta condiciona ou transforma a concepção de avaliação institucional no AVALIES. Constatou-se que, no SINAES, o Estado tende a estabelecer os parâmetros do AVALIES em detrimento da comunidade universitária e da sociedade civil, para legitimar a adoção de gestão de políticas públicas de avaliação voltadas aos novos moldes da regulação e modernização das Instituições de Educação Superior. Também assume a responsabilidade de ordenar e controlar a adoção do modelo e dos processos de avaliação, desvirtuando a concepção de avaliação institucional democrática e comprometendo a coerência avaliativa entre a dimensão nacional e a especificidade de cada instituição avaliada.

No quarto banco de produção científica, a Biblioteca Digital Brasileira de Teses e Dissertações (BDTD- IBICT), pudemos encontrar o trabalho de Souza (2013), intitulado "Políticas públicas em educação superior no Brasil: análise do Exame 
Nacional de Desempenho de Estudantes-ENADE- na perspectiva do modelo do Ciclo Político", que teve por objetivo analisar o ciclo político do ENADE enquanto um dos instrumentos de avaliação da educação superior e de orientação para os gestores dos cursos e das instituições de ensino superior do Brasil. Concluiu-se que os resultados do ENADE produzem vários tipos de dados que podem ser classificados pelas instituições de educação superior por categoria administrativa, organização acadêmica, região geográfica, modalidade de ensino, dentre outras. Esses dados permitem a definição de ações voltadas para a melhoria da qualidade dos cursos por parte dos gestores universitários. Conclui-se, ainda, que a centralidade do ENADE nos processos avaliativos deve ser questionada. É necessário analisar o conjunto da avaliação e não apenas o desempenho dos estudantes desarticulado de outros instrumentos avaliativos.

O quinto e último banco de teses e dissertações, o Repositório Institucional da Universidade de Brasília (UnB), nos possibilitou encontrar a tese de Gontijo (2014), com o título "Implicações do ENADE para a organização do trabalho pedagógico e as práticas avaliativas em um curso de Pedagogia", que se volta para analisar as implicações do ENADE para o desenvolvimento do trabalho pedagógico e das práticas avaliativas de um curso de Pedagogia de uma Instituição de Ensino Superior do Distrito Federal/Brasil, em relação às possíveis influências do ENADE na organização do trabalho pedagógico do curso e das práticas avaliativas desenvolvidas em sala de aula. Seus resultados apontam sua influência na organização do trabalho pedagógico do curso de Pedagogia, pelo fato de ele ser parte significativa do processo avaliativo ao qual se submetem educadores em formação.

\section{CONSIDERAÇÕES FINAIS}

Diante do levantamento realizado, pode-se constatar que a partir da década de 2000 houve um avanço no número de pesquisas que buscam inteirar-se e compreender a dinâmica do percurso das políticas de avaliação para a educação superior no Brasil. Estas têm demonstrado uma preocupação quanto a identificação das redes de influência (crises econômicas e políticas, reformas e diminuição no papel do Estado, estímulo à iniciativa privada e outros fatores) que têm mobilizado a elaboração, implementação e fiscalização destas políticas. É possível perceber também que as pesquisas se voltam a compreender as novas estruturações para avaliação da formação de nível superior, buscando conhecer as funções e os objetivos dos novos modelos impostos legalmente. Para além disto, se propõe a realizar análises comparativas entre as políticas de 
avaliação anteriores com o sistema atual, com o intuito de reconhecerem avanços, limites e/ou retrocessos.

Os trabalhos têm apontado diferentes questões quanto a influência das políticas de avaliação externa, em especial o ENADE, para a formação de docentes. Entre estas questões, estão: o percurso histórico de elaboração de políticas de avaliação da educação superior no Brasil (BARREYRO e ROTHEN, 2014; BERTOLIN e MARCON, 2015); a incompreensão dos objetivos de avaliação do ENADE por parte das IES e do próprio Estado, funcionando como instrumento de regulamentação do MEC, pouco utilizado pelas IES para a proposição e implementação de melhorias voltadas à qualidade da formação oferecida (RANGEL, 2010; SILVA, 2009; SOUZA, 2013); a avaliação enquanto instrumento de classificação com ênfase no controle (FERRAZ, 2006; SILVA, 2015); avaliação enquanto possibilidade de mudanças institucionais (CUNHA, 2011); ENADE enquanto influenciador da organização do trabalho pedagógico, das práticas na sala de aula no curso de Pedagogia (GONTIJO, 2014); avaliação externa como meio possível para compreensão da organização da gestão das IES e da influência que esta organização exerce sobre a formação de estudantes (BORDAS et al, 2008; LACERDA E FERRI, 2015; SILVA, 2013; SOUZA, 2013; BARBOSA, FREIRE e CRISÓSTOMO, 2011).

Neste sentido, depreendemos que a contribuição essencial da nossa pesquisa de Mestrado, consiste em conhecer, compreender e promover uma discussão sobre a pertinência da prática de avaliação de larga escala para o contexto local da UFPE em seu centro localizado no município de Caruaru- PE, problematizando os reflexos do ENADE para o espaço da formação inicial dos estudantes de Pedagogia, afim de saber se o aparato legal que rege a constituição da política do exame, é considerado de maneira plena pela IES e quais os impactos que este processo vem a acarretar na formação dos estudantes.

\section{Referências Bibliográficas}

BARBOSA, Glauber de Castro; FREIRE, Fátima de Souza; CRISÓSTOMO, Vicente Lima. Análise dos indicadores de gestão das IFES e o desempenho discente no ENADE. Avaliação, Campinas; Sorocaba, SP, v. 16, n. 2, p. 317-344, jul. 2011. 
BARREIRO, Gladys Beatriz; ROTHEN, José Carlos. Percurso da avaliação da educação superior nos governos Lula. Educ. Pesqui., São Paulo, v. 40, n. 1, p. 61-76, jan./mar. 2014.

BRASIL. Presidência da República. Lei $n^{0} 10.861$, de 14 de abril de 2004. Institui o Sistema Nacional de Avaliação da Educação Superior (SINAES). Disponível em: <www.planalto.gov.br/ccivil_03/_ato2004-2006/2004/lei/110.861.htm>. Acesso em: setembro de 2014.

BERTOLIN, Júlio C. G.; MARCON, Telmo. O (des)entendimento de qualidade na educação superior brasileira- das quimeras do Provão e do ENADE à realidade do capital cultural dos estudantes. Avaliação, Campinas; Sorocaba, SP, v. 20, n. 1, p. 105122, mar. 2015.

BORDAS, Merion Campos, et al. O olhar da comissão assessora de avaliação sobre o ENADE da área de Pedagogia- 2005. Avaliação, Campinas; Sorocaba, SP, v. 13, n. 3, p. 681-712, nov. 2008.

BRITO, Márcia Regina Ferreira de. ENADE 2005: perfil, desempenho e razão da opção dos estudantes pelas Licenciaturas. Avaliação, Campinas; Sorocaba, SP, v. 12, n. 3, p. 401-443, set. 2007.

CUNHA, Kátia Silva. O discurso da avaliação institucional trajetória articulada no campo das políticas educacionais: um estudo de caso. Repositório Institucional da UFPE. Tese (Doutorado)- Universidade Federal de Pernambuco. CE. Educação, 2011. URI: http://repositorio.ufpe.br/handle/123456789/4177. Acesso em: setembro de 2016. FERRAZ, Bruna Tarcília. Políticas de avaliação para a educação superior: um estudo analítico sobre as práticas discursivas nos governos de Fernando Henrique Cardoso e Luís Inácio Lula da Silva. Repositório Institucional da UFPE. Dissertação (Mestrado)- Universidade Federal de Pernambuco. CE. Educação, 2006. Disponível em: http://repositorio.ufpe.br/xmlui/bitstream/handle/123456789/4452/arquivo5308_1.pdf?s equence $=1 \&$ is Allowed=y. Acesso em: setembro de 2016.

FERREIRA, Norma Sandra de Almeida. As pesquisas denominadas "estado da arte". Educação \& Sociedade, ano XXIII, nº 79, Agosto/2002.

GONTIJO, Simone Braz Ferreira. Implicações do ENADE para a organização do trabalho pedagógico e as práticas avaliativas em um curso de Pedagogia. Repositório Institucional da UnB. Tese (Doutorado). Faculdade de Educação. Programa de Pósgraduação em $\quad$ Educação, $2014 . \quad$ Disponível http://repositorio.unb.br/handle/10482/16027. Acesso em: setembro de 2016. 
LACERDA, Leo Lynce Valle de; FERRI, Cássia. Relações entre indicadores de qualidade de ensino e desempenho de estudantes dos cursos de Pedagogia do Brasil no Exame Nacional de Desempenho de Estudantes. Rev. bras. Estud. pedagog. (online), Brasília, v. 96, n. 242, p. 129-145, jan./abr. 2015.

RANGEL, Maria Luiza Nogueira. O Exame Nacional de Desempenho de Estudantes no curso de pedagogia da UnB: avanços, limites e desafios. 2010. xviii, 244 f., il. Dissertação (Mestrado em Educação)- Universidade de Brasília, Brasília, 2010. Disponível em: http://repositorio.unb.br/handle/10482/9076 . Acesso em: setembro de 2016.

SILVA, Assis Leão da. Avaliação do ensino superior: a dinâmica de implementação do SINAES nas universidades federais no tocante ao instrumento de avaliação interna- CPA. Dissertação (Mestrado)- Universidade Federal de Pernambuco. CE. Educação, 2009. URI: http://repositorio.ufpe.br/handle/123456789/4885. Acesso em: setembro de 2016.

Avaliação institucional no Sistema Nacional de avaliação da

Educação Superior (SINAES). Tese de Doutorado- Universidade Federal de Pernambuco. CE. Educação, 2015.

SILVA, Edcleide Maria da. Aspectos contextuais e metodológicos da avaliação da qualidade da educação superior brasileira: uma análise dos indicadores utilizados pelos órgãos reguladores nos processos de avaliação dos cursos de graduação. Dissertação (Mestrado)- Universidade Federal de Pernambuco. CE. Educação, 2013. URI: http://repositorio.ufpe.br/handle/123456789/11366. Acesso em: setembro de 2016.

SOUZA, Lúcia Helena Gazolla Reis de. Políticas públicas em educação superior no Brasil: análise do Exame Nacional de Desempenho de Estudantes-ENADE- na perspectiva do modelo do Ciclo Político. Viçosa, MG, 2013. URI: http://repositorio.ufv.br/handle/123456789/1970. Acesso em: setembro de 2016. 